\title{
Portal for Families Overcoming Neurodevelopmental Disorders (PFOND): Implementation of a Software Framework for Facilitated Community Website Creation by Nontechnical Volunteers
}

Xin Cynthia $\mathrm{Ye}^{1^{*}}$, BSc; Isaiah $\mathrm{Ng}^{1 *}$, BAppSc; Puya Seid-Karbasi ${ }^{1 *}$; Tuhina Imam ${ }^{2}$, MSc; Cheryl E Lee ${ }^{2}$, BA; Shirley Yu Chen ${ }^{2}$; Adam Herman ${ }^{2}$, BSc; Balraj Sharma ${ }^{2}$; Gurinder Johal ${ }^{2}$; Bobby Gu$^{2}$; Wyeth W Wasserman ${ }^{1}, \mathrm{PhD}$

${ }^{1}$ Centre for Molecular Medicine and Therapeutics, Child and Family Research Institute, Department of Medical Genetics, University of British Columbia, Vancouver, BC, Canada

${ }^{2}$ PFOND Volunteer Editor, Vancouver, BC, Canada

*these authors contributed equally

Corresponding Author:

Wyeth W Wasserman, PhD

Centre for Molecular Medicine and Therapeutics, Child and Family Research Institute

Department of Medical Genetics

University of British Columbia

Room 3103, CMMT

950 West 28th Avenue

Vancouver, BC, V5Z 4H4

Canada

Phone: 1 (604) 8753812

Fax: 1 (604) 8753819

Email: wyeth@cmmt.ubc.ca

\section{Abstract}

Background: The Portal for Families Overcoming Neurodevelopmental Disorders (PFOND) provides a structured Internet interface for the sharing of information with individuals struggling with the consequences of rare developmental disorders. Large disease-impacted communities can support fundraising organizations that disseminate Web-based information through elegant websites run by professional staff. Such quality resources for families challenged by rare disorders are infrequently produced and, when available, are often dependent upon the continued efforts of a single individual.

Objective: The project endeavors to create an intuitive Web-based software system that allows a volunteer with limited technical computer skills to produce a useful rare disease website in a short time period. Such a system should provide access to emerging news and research findings, facilitate community participation, present summary information about the disorder, and allow for transient management by volunteers who are likely to change periodically.

Methods: The prototype portal was implemented using the WordPress software system with both existing and customized supplementary plug-in software modules. Gamification scoring features were implemented in a module, allowing editors to measure progress. The system was installed on a Linux-based computer server, accessible across the Internet through standard Web browsers.

Results: A prototype PFOND system was implemented and tested. The prototype system features a structured organization with distinct partitions for background information, recent publications, and community discussions. The software design allows volunteer editors to create a themed website, implement a limited set of topic pages, and connect the software to dynamic RSS feeds providing information about recent news or advances. The prototype was assessed by a fraction of the disease sites developed ( 8 out of 27), including Aarskog-Scott syndrome, Aniridia, Adams-Oliver syndrome, Cat Eye syndrome, Kabuki syndrome, Leigh syndrome, Peters anomaly, and Rothmund-Thomson syndrome. The editor progress score was used to measure performance for a portion of sites.

Conclusions: The PFOND system provides a convenient and structured Internet resource for the facilitated creation of information resources for families confronted by rare disorders. The system empowers volunteers to participate in the creation of quality content, while allowing for the inevitable turnover of contributors over time. The next phase of PFOND development will focus on volunteer participation in system development and community engagement. 
(JMIR Res Protoc 2013;2(2):e25) doi: 10.2196/resprot.2675

\section{KEYWORDS}

medical informatics; medical genetics; inborn genetic disease; rare disease; social media; consumer participation

\section{Introduction}

The general public uses the Internet as a primary source to obtain health information, with roughly $4 \%$ of all Internet queries being health-related [1]. The majority of Internet users have obtained health information online [2,3]. There are rich sources of online medical information, exemplified by MedlinePlus, WebMD, the Mayo Clinic information portal, and Yahoo! Health [4]. Genetic disorders constitute an important subset of human disease in which DNA sequence variations fully cause or partially contribute to the disease [5]. Information about genetic diseases can be accessed online for many disorders [6-8], with the Online Mendelian Inheritance in Man (OMIM) site being one of the most enduring disease information resources [9]. Wikipedia, one of the most widely read health information resources, contains articles about many disorders [10,11]. For individual disorders, online communities may form to share information and to provide support for families struggling with the arising challenges. The popular Facebook and Twitter platforms host more than 200 breast cancer groups and 500 diabetes groups [12]. Diverse resources have been developed commercially to promote exchange between patients (eg, PatientsLikeMe) [13], while some robust communities participate in discussion boards such as that provided by Yahoo (eg, EyesApart for strabismics) [14].

A subset of genetic disorders benefits from strong support by nonprofit or academic organizations that deliver high-quality content through polished websites. For instance, the Huntington Disease Society of America maintains a website providing extensive information for families afflicted with the disease [15]. Similarly, the Cystic Fibrosis Foundation supports CF families with informative content [16]. Unfortunately, such robust information and resources are not available for many families confronted with rare genetic disorders [10], where rare refers to disorders arising in less than $\sim 5$ per 10,000 individuals [17]. While each disorder by definition impacts a small number of families, an estimated 7000 rare disorders impact a substantial population. For example, 25-30 million patients in the United States and 27-36 million patients within 25 European Union countries are impacted. When including a family member or a caregiver, the number of people directly affected by rare disorders approaches 100 million in the United States and the European Union [18]. Resources with broad coverage of rare genetic disorders include OMIM, GeneTests, and OrphaNet. These sites provide information for research professionals but have limited content for the general public $[19,20]$. The challenge posed to rare disease communities is enormous. It is recognized that such communities may receive less attention for the development of therapeutics [21], expert clinicians are more likely to be geographically inaccessible [18], and they may never encounter another family facing the same challenges $[18,22]$.
Families confronted with rare genetic disorders face the challenge of finding useful information about the characteristics of the disease, guidance for the care of the afflicted family member, and news of emerging research findings [17,23,24]. Periodically a website or Facebook page may be created providing some information or links, but such resources are usually poorly maintained over time [25]. The developers of these sites may not have the technical skills to provide a complete set of features, may lack the communication skills to convey complex topics to a lay audience, and in most cases will have limited endurance for the hard work required to communicate within a small global population of interested individuals, especially if simultaneously struggling to provide care to impacted family members $[26,27]$.

We have developed an Internet-based information portal designed to allow volunteer editors to manage delivery of information about rare disorders. Originally envisioned with a focus on neurodevelopment and subsequently broadened, the Portal for Families Overcoming Neurodevelopmental Disorders (PFOND) is a prototype Internet service that provides a basic set of automated functions and information about selected rare disorders. It delivers news items and summaries of recent scientific articles about a disorder and can support a discussion board when moderators are available. When a member of the public is available to participate in the management of a topic, the system allows for their participation in the editorial process. As a volunteer editor, the individual can compile more extensive information about a disorder, create articles, incorporate links to information resources, and oversee the discussion board. At the conclusion of a volunteer editor's effort, the enriched content is maintained until a new volunteer is engaged to focus on the disorder page. This novel fusion of dynamic and static content within PFOND is intended to provide a basic ongoing functionality, while allowing enriched content when dedicated volunteers are available. As this report focuses on the initial development of PFOND, we assess the fraction of initial sites successfully developed and the first phase development of a gamification-based scoring procedure to encourage editor participation. In addition to providing information for and promoting the sharing of experience between families struggling with rare genetic disorders, PFOND is intended to draw clinical research and social attention to rare genetic disease as a whole.

\section{Methods}

\section{Content Management Software}

To facilitate the long-term maintenance of PFOND, the websites must be readily modified and moderated by individuals with limited technical expertise. Highly customized disease information pages are difficult to maintain without a dedicated administrator or Web developer. Depending on available resources, and acknowledging the dedicated and long-term efforts of some developers, such sites may stagnate with little new content and outdated styling. The use of Content 
Management Systems (CMS) reduces the upkeep cost by providing graphical interfaces through which volunteer editors can efficiently manage a site [28].

WordPress is an open-source blog tool and publishing platform implemented with PHP scripting language and MySQL database software. It is best known for its free hosting service, which is streamlined for blogging [29]. The software provides many additional features that make it a suitable CMS for this project [28]. It has been used to build successful sites for businesses, education, media, and others. This popularity has resulted in a broad community of users worldwide familiar with the software interface and a strong pool of online and published user guides and training manuals [28].

WordPress was chosen over other potential systems (eg, Drupal, Joomla!) for the following reasons:

- Its popularity means there are a variety of available "plugins" (software that can be installed into the system to provide additional functionality), many of which are suitable for inclusion in PFOND.

- It is maintained by hundreds of developers and contributors who provide ongoing support, additions, plugins, and fixes, thus minimizing the risk of the system becoming obsolete.

- The administrative interface (used by editors to manage content on the site) is preferred over other systems as it is easier to learn and navigate.
- As an open-source project, the software is freely available for this unfunded, community service project.

\section{Website Customization}

To minimize development costs, WordPress plugins were used extensively to implement system functionality, including discussion board and newsfeed features. Table 1 lists the plugins that are used in the PFOND system. Additional plugin information can be found on the WordPress website [30].

Specific features not available from existing plugins had to be implemented de novo. By default, WordPress allows only two types of content to be created: posts, which hold dynamic, blog-like entries; and pages, which are meant to hold static content such as site or contact information. To provide support for customized sections of the site, new post types (types of content) and page templates (PHP scripts that control how a page displays information) were added. These custom features facilitate or allow editors to add and manage a list of information about a disease, research experts, and external sites related to the disease; the About, Experts, and Links pages to automatically sort and display information and provide options for visitors to navigate through them; and the News Page to properly display items generated using the automatic feed syndicator.

In addition, custom widgets allow editors to configure content in their site's one or more sidebars. For example, widgets can show Google results for any search term, a list of new members, and recent forum posts.

Table 1. Utilized WordPress plugin modules.

\begin{tabular}{|c|c|c|}
\hline Plugin & Author & Description \\
\hline Achievements & Paul Gibbs & Allows for the gamification of certain Wordpress actions \\
\hline Adminize & Frank Bültge & $\begin{array}{l}\text { Fine-tune user access to backend functions by hiding unnecessary items } \\
\text { from WordPress administration menu }\end{array}$ \\
\hline BuddyPress & Open source & Provides social networking functions such as user profiles and forums \\
\hline FeedWordPress & Charles Johnson & Provides Atom/RSS syndication to collect articles for the News Page \\
\hline Multisite Global Search & Alicia García Holgado & Adds the ability to search the content of the individual disorder websites \\
\hline Multisite User Management & Brent Shepherd & Assigns default roles for new users that join the site \\
\hline Site Creation Wizard & Jon Gaulding, Ioannis Yessios & Allow users to create a site using predefined templates \\
\hline Widget Context & Kaspars Dambis & Controls which widgets are displayed on which pages \\
\hline
\end{tabular}

\section{Site Theme}

The typical visitor will never see the back-end system. Unless they volunteer to participate in the editorial process, users will engage the system through the graphical front-end. Hence, the website's design plays a significant factor in attracting and serving its target community. The fonts, colors, and layouts of WordPress sites are controlled by "themes"-many of which are available for download online. For the pilot project, a customized PFOND theme was created to establish a look and feel for future PFOND sites. The following factors were taken into consideration:

- Navigation: The site should be easy to navigate, allowing new visitors to quickly find the information they seek. This

has been accomplished, in part, by keeping a relatively "flat" menu hierarchy.

- Simplicity: A cleaner design is preferred to minimize loading times and allow nontechnical users to more easily navigate the site.

- Customizability: Colors, fonts, banners, and other elements can be changed without disrupting the design.

\section{Multisite and Site Templates}

Two important aspects of PFOND are the ability to generate new disease sites in a simple manner, and the capacity to share selected forum posts, news, and disease information across sites. It is expected that a network of sites can have a greater impact on disease communities through the exchange of ideas and information. These goals were achieved using the WordPress multisite feature, which allows multiple, independent sites to 
operate under a common WordPress installation. Using plugins and custom scripting, the multisite feature can be adapted to include global search results and discussion boards.

The site creation process was designed with simplicity as the primary consideration. Administrators generate a new site by filling in a form to specify the desired URL, disease name, and site title. New sites are created using a default standard template, and each site allows for independent but limited customizations. The standard template contains a set of predetermined widgets, sample pages, and posts, and other visual settings, which enable editors to set up the site with few steps and therefore maintain a focus on site content.

\section{Additional Software Technologies and Download Information}

A dedicated virtual server running CentOS was established to host the system. The following technologies were used in the development of the PFOND prototype: HTML, CSS, JavaScript, PHP, MySQL, and Apache Web Server. The software components introduced in this manuscript can be downloaded from the GitHub software repository [31].

\section{Motivation Mechanisms Within the Pilot Project}

Two phases of testing were performed to assess system stability and usability. We recruited 8 volunteers in the alpha phase and an additional 74 volunteers in the beta phase. Two motivation mechanisms were introduced: communication and gamification-based feedback scoring. Personal email communications and small group meetings were conducted, informing volunteers about the project and encouraging their engaged interest. As the project scale increased, we implemented an achievement scoring system and other gamification features to guide the editors through the website construction and allow them to assess their performance relative to that of other editors.

\section{Results}

\section{Overview of the PFOND Content}

The PFOND system was implemented as described above in the Methods section. The resulting website will be described as a walk-through of the key pages encountered by the users of the system. For each disorder, four sections are generated, including a home page, a disease information page, a news page, and a discussion board. The pages are illustrated in Figures 1 and 2 . The editor interface is described in a subsequent section.

The PFOND homepage for a disorder provides a summary of recent information. The editor can supply a front-page feature article, while the remaining sections are automatically extracted from online sources or internal pages of the system. In addition to the feature article, the page displays recent news articles about the disorder (obtained from Google News), recent internal posts from the "Community" or online resource links (from system users), and notifications about changes to the PFOND system.

There are four key subsections for each disorder. The "About" page contains information about the disorder, including a sidebar that facilitates navigation. The "Overview" section describes the characteristics of the disorder and the frequency in different populations. The "Diagnosis and Treatment" section provides information about available tests and treatments. The "Research" section provides an academic perspective of the disease, including an introduction of the underlying mechanisms when known. While the creation of the material displayed on this page represents the greatest contribution of volunteer editors, it is static and therefore the last modification date is clearly presented to inform readers of its currency.

The "Experts" page contains information about researchers active in areas related to the disease, and summaries about their work convey how the disease is currently studied. In addition to the informative summaries of research interests, a link to a website of each identified expert is provided to facilitate access to emerging findings (if available). The information on this page is particularly helpful to a new volunteer editor attempting to build upon the foundation of a departed volunteer. In the testing phase of the project, concerns were raised about providing clinical expert contact information without authorization or in-depth knowledge. As volunteer editors are not qualified to judge the quality of practitioners, the focus of this page is restricted to active researchers in the field and information presented is obtained from each researcher's website. A warning is provided to readers to indicate that the list does not represent an endorsement or recommendation of the listed individuals.

The "News" pages present articles related to the disorder, from both lay and scientific sources. When a volunteer editor is engaged, the editor can select articles to feature on the system, providing a brief summary of the content and a link to its original source. The content of this page is predominantly produced by automated methods set-up and refined by a volunteer editor. Two key sources are displayed. A news feed is presented using the Google Alerts service, which is constrained by a set of search terms specified by the editor. Scientific articles reported in the Medline database are obtained from the PubMed RSS Feed service in a similar manner. This automation allows the user community to find recent information despite the transient attention of volunteer editors.

While editors are active, readers can use the discussion board under the "Community" page to share their understanding, questions, and stories with other members. Discussion boards provide a record of past issues for future readers to draw upon. Furthermore, the social networking on discussion boards can provide peer support for families. However, discussion boards are the most challenging aspect of PFOND. Maintaining high-quality content and minimizing "spam" and inappropriate text requires editorial review of the board contents. Given the necessity of timely posting and the focus on volunteer editors as moderators, manual review of these posts may not be possible. Blogs with large and active readership have found community-based methods to "vote down" bad content, but the nature of a rare disorders system means the readership may be strikingly small and therefore unable to support such participatory filtering. While the PFOND system has been implemented with discussion board features, the board is activated only when a volunteer indicates a commitment to facilitate the discussion on a regular basis. In the discussion section, we raise the challenging issue of how nonexpert editors should handle difficult questions or situations arising in a discussion board. 


\section{Editor Interface}

The operating interface (Dashboard) used by volunteer editors is structured in a simple format to serve two purposes (Figure 3 ). First, we seek to minimize the time required for volunteers to learn the system. Many of the options presented by default in the Wordpress Dashboard were removed, leaving the volunteers with less distraction. Second, the removal of or limited user access reduces the chance for unintended disruptions to the PFOND service.

Figure 1. Introducing PFOND. Screenshots of the PFOND system homepage surrounded by images of selected disorder home pages, including aniridia, Cat Eye Syndrome, and Rothmund-Thomson syndrome.

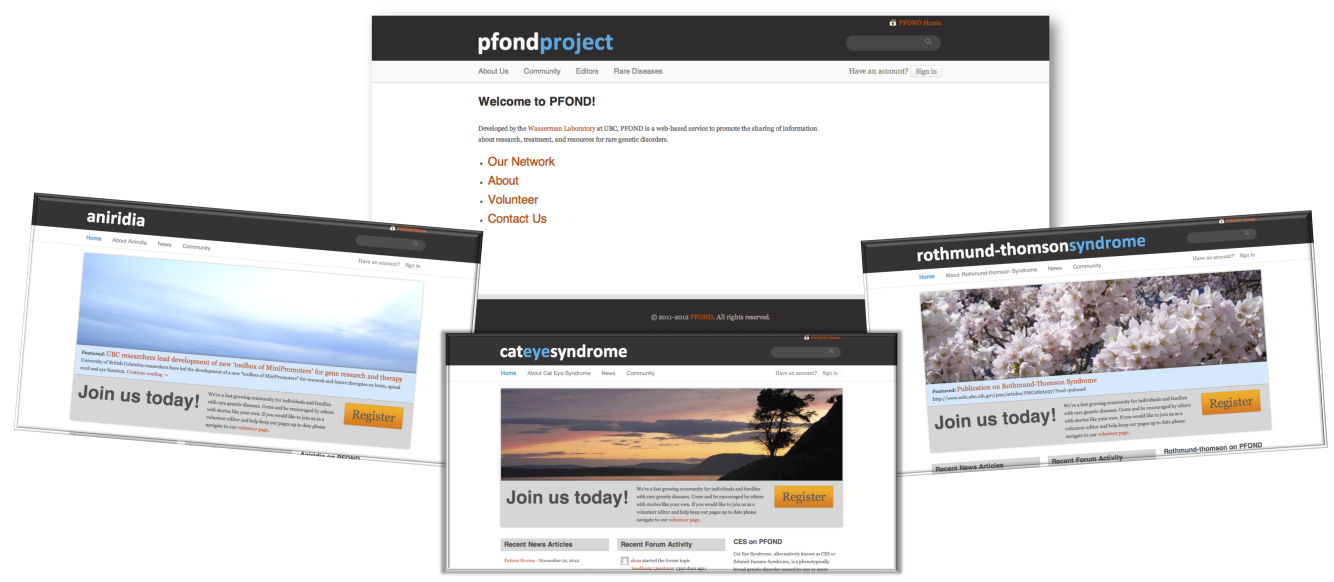

Figure 2. Selected components of a PFOND site for Kabuki Syndrome (Home page, About page, News page).

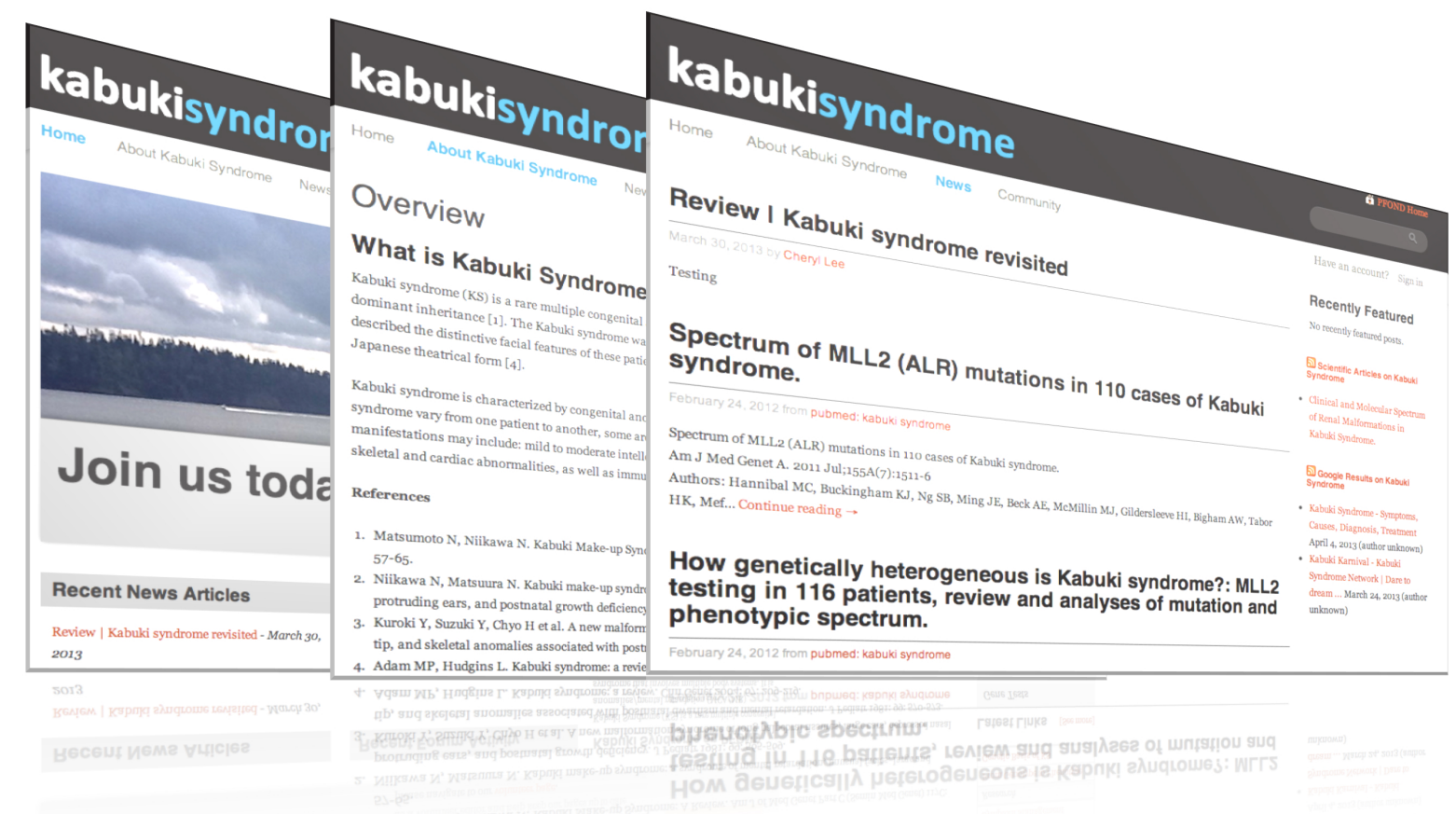


Figure 3. Selected views of the PFOND editor interface.

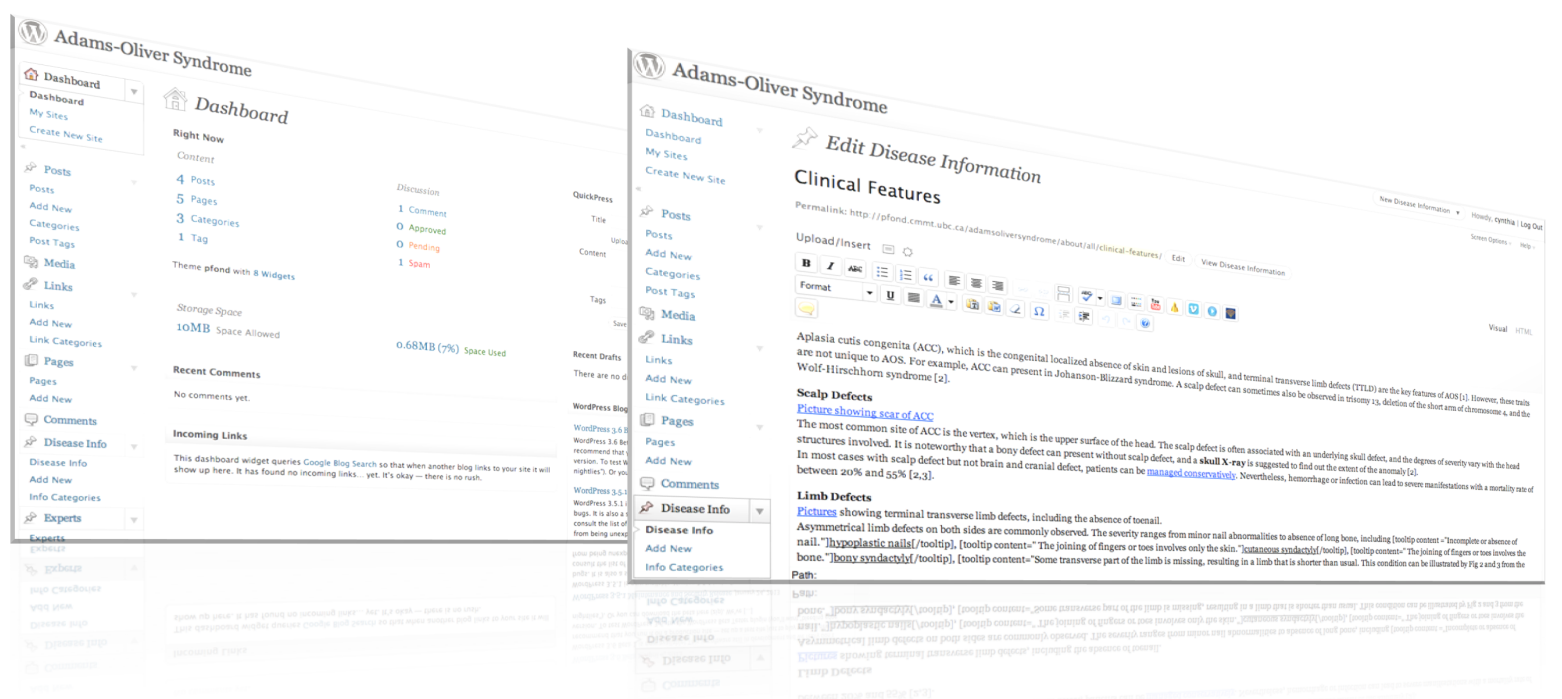

\section{Pilot Project}

To validate the software and confirm the utility of the interface for efficient volunteer utilization, a two-phase pilot project was performed.

\section{Volunteer Recruitment}

The model for PFOND is dependent upon the recruitment of volunteer editors to provide content and facilitate creation of new disease sites. In order to test the system, two stages of volunteer recruitment were conducted. In the first alpha-phase, volunteer requests were distributed within the University of British Columbia (UBC) Department of Medical Genetics and the Centre for Molecular Medicine and Therapeutics, seeking referrals to potential volunteers. A set of 8 individuals responded and registered on the system. An introductory in-person session was conducted. Four disease sites were initiated. In the beta phase, we recruited an additional 74 volunteers through announcements on UBC Career Services volunteer board, all physically based in the surrounding community (in order to offer an initial face-to-face introduction to the project, attended by 20 volunteers). A total of 27 disease sites were launched, of which five were topics specifically requested by volunteers.

\section{Testing the PFOND Software}

The testing of the system was performed by the recruited volunteer editors, following the process depicted in Multimedia Appendix 1 . The goal of the initial study with 8 volunteers was twofold: to test the stability of the system and to test the usability of the editor interface. The identified system problems (10 in total were recorded) were addressed immediately by the website programmer, and the suggestions on design were compiled and discussed for potential future incorporation. In the second phase, we sought to further test the stability of the online system and gather feedback about new features. Moreover, we shifted from a combined training and communication method (online and face-to-face) to an online-only approach. The beta phase of testing was intended to allow transition from local volunteers to a global community. The prototype testing was limited to a set of basic aspects, including ease of use, customizability, community access, and automated news aggregation. For ease of use, the beta-testing process confirmed that the volunteer editors could use and maintain their sites without advanced technical knowledge. A subset of editors elected to customize fonts, colors, headers, and menus, confirming the capacity of the system to facilitate customization. Each volunteer editor established an automatic news aggregation feed by establishing and managing subscriptions to news and scientific articles. With 8 "published" PFOND sites online, the process confirmed that new disease sites could be created with relative ease.

\section{Feedback Mechanisms}

Multiple approaches were tested for providing feedback to volunteers about their progress. Each volunteer editor had the opportunity to file a monthly report indicating his or her work 
on the system, to which directed responses were provided. Such reports were used as a means for tracking the engagement of the volunteers and to identify disease sites to which additional editors could be assigned. Volunteers could request a review of their work and an assessment of the work remaining to bring the quality of their disease site content to a level suitable for release of the site to the public, which occurred for 4 out of 23 volunteer teams.

Based on previous experience with development of the Transcription Factor Encyclopedia [32], the developers recognized that editors benefit from measureable goals. Thus, a scoring procedure was implemented in which editors were automatically assigned points for specific tasks to guide and motivate editors throughout the development process (Figure 4). Information about some rewards was provided on the system, while other rewards were surprises intended to encourage volunteers to surpass the minimal goals specified (Table 1). The achievement system was part of a broader gamification strategy to engage participants (Table 2). Gamification is not limited to digital technology [33,34], and meaningful gamification requires user-centered design [35]. The use of external rewards to control behavior risks the nongame context being perceived negatively [35]. Adopted from Deci and Ryan's "self-determination theory", three innate needs for intrinsic motivation have been identified and described in the context of gamification [34,36]. Within our initial framework, PFOND meets some of these criteria. Since users can integrate the activity with their personal goals and needs, the activity is likely to be perceived as positive [35]. Table 2 lists the point values assigned to specific achievements by editors. The contributions of volunteers can be assessed in part by the points earned. Table 3 shows the coverage of gamification mechanisms within the current implementation.

\section{Released PFOND Sites}

A total of 8 PFOND sites have been released (ie, "published") on the system, of which 4 were created entirely by volunteer editors and 4 were created with participation of the development team. The initial pre-alpha testing of the site focused on aniridia, for which the Aniridia Foundation International (AFI) allowed us to incorporate information from their outreach website. An automated message indicates the source and encourages readers to go to the AFI site for the most current information. The published volunteer contributions address Aarskog-Scott Syndrome (ASS), Cat Eye Syndrome, Kabuki Syndrome, and Rothmund-Thomson Syndrome. Three were assigned topics and one (ASS) was a volunteer-requested topic. The volunteers with published websites are included as authors on this report, consistent with their important contributions to the project.

Table 2. PFOND feedback scoring.

\begin{tabular}{lll}
\hline Entry & Score & Expected \\
\hline New editor status & 2500 & 2500 \\
Monthly report & $1000 /$ month & 3000 \\
Image & $2500 /$ image & 2500 \\
Forum activities (PFOND-wide activities) & 2500 for the 1st time, 5th time, 10th time; 1000 for the & 7500 \\
& 20 th, 30th, 40th, etc, up to 90th & 1000 \\
Profile update (hidden) & 500 for the 1st, 3rd, 5th & 3000 \\
Tooltip activation & 1000 for the 1st, 5th, 10th; 5000 for the 25th & 5000 \\
RSS feeds & $2500 /$ each & 15,500 \\
News & For the 1st post: 2500; from the 2nd to the 10th post: & 3000 \\
Research expert & $1000 /$ each; 2500 for the 20th, 30th, 40th, etc & 2000 \\
Submission for site review & $1000 /$ each, up to 3000 points & 20,000 \\
Approval for site & $1000 /$ each & 20,000 \\
Disease information & 1 st: 2500; 5th, 10th, 25th, 50th: 1000/each; 100th: 5000 & 5500 \\
Total & & 70,500 \\
Maximum & & 100,000
\end{tabular}


Table 3. Relationship between PFOND and the three innate needs for successful motivation by gamification as proposed by Deci and Ryan [33,35].

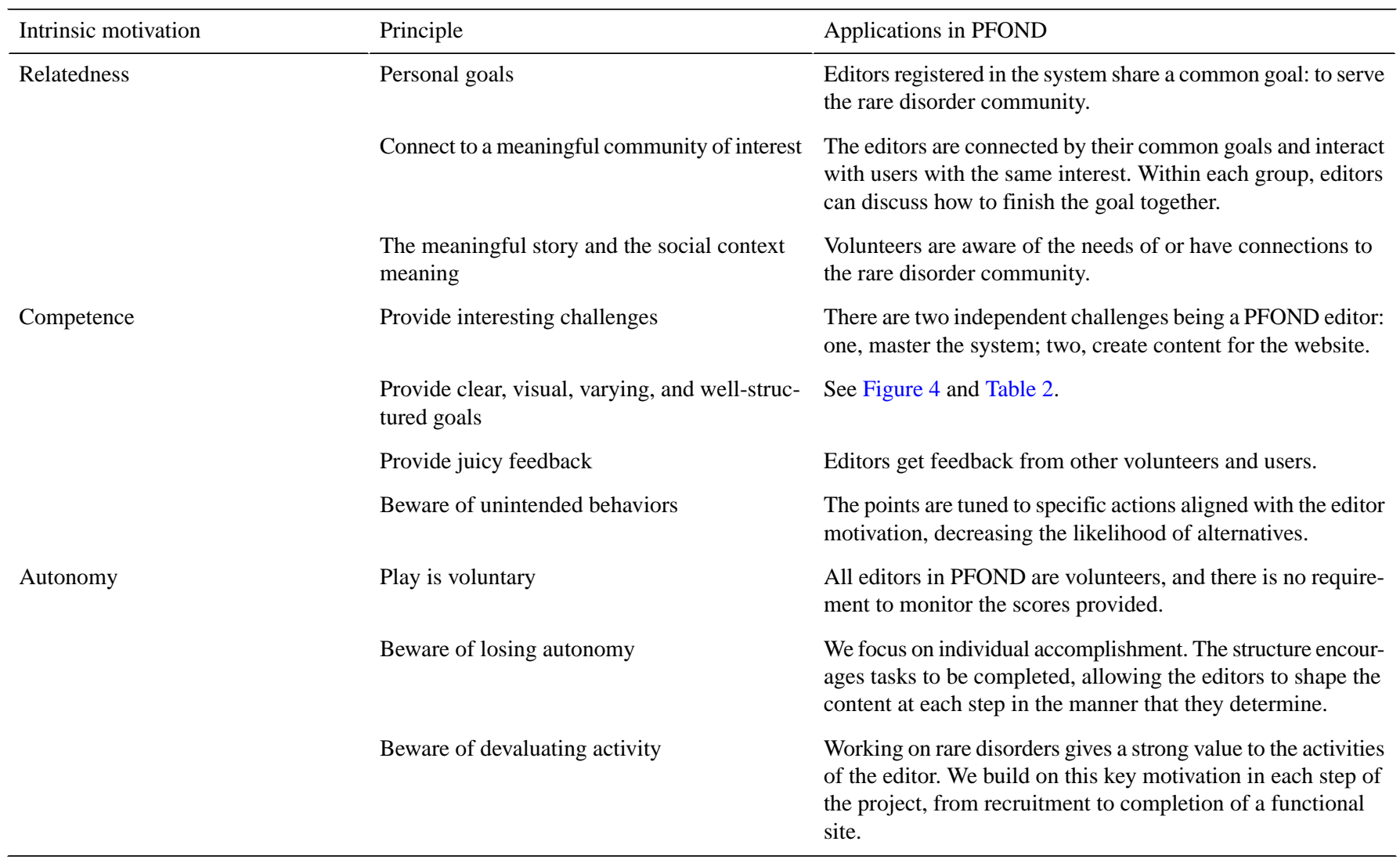

Figure 4. Achievements scoring system.

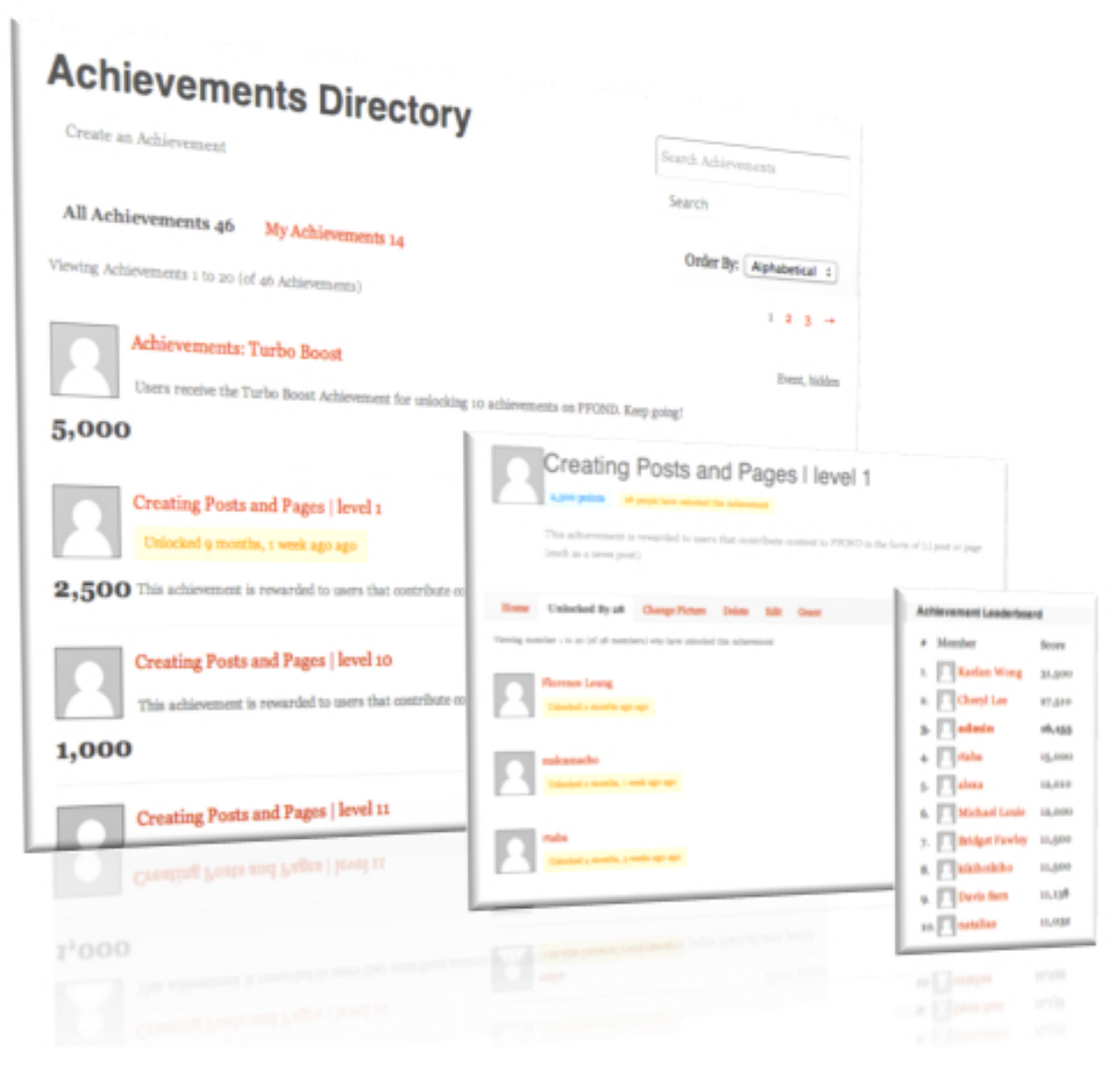




\section{Discussion}

\section{Principal Findings}

The PFOND project provides an intuitive Web-based software system to enable the creation and maintenance of websites for rare genetic diseases. It is intended to allow nontechnical editors to participate in the creation and delivery of disease information informed by scientific research. Grouping services for diverse disorders within one framework offers several potential advantages: (1) greater public awareness of available resources, (2) shared technical challenges to allow volunteers to focus on quality content rather than system management, (3) the capability to share information across communities where appropriate, and (4) the opportunity for transitioning between volunteer editors over the long-term to accommodate the transient nature of volunteer editor service. Most importantly, PFOND aims to provide a cyber home for patients and their families.

The development of PFOND addresses an information gap for rare diseases. Key resources can be identified for each disorder and presented in an easily accessible format. Although the information in no way diminishes the necessity for professional advice and counselling, families provided with improved online information about emerging clinical research may develop a deeper understanding and therefore be better equipped to discuss matters and concerns with their health care providers [37-39] Ideally, the information presented would accelerate the dissemination of information about identification of beneficial approaches to the disorder, such as available treatments, dietary changes, or useful devices $[39,40]$.

Online resources such as PFOND promote awareness that there are other families facing similar challenges, which may help alleviate any sense of isolation [18,24]. For sites with an actively moderated discussion forum, users will have the opportunity to directly engage with peers to gain insights from their experience and diverse information sources $[41,42]$. While there are risks of inaccurate information, some studies suggest such problems may be infrequent $[43,44]$. Nevertheless, the risk remains that users may present claims and suggestions that may be inaccurate or inappropriate. While moderation can reduce the potential problem, the fact that PFOND is maintained by volunteers with no requisite training results in two choices: (1) exclude the benefits of forum interactions from the site or (2) include a clear warning to users that information presented in forums may not be reliable. Recent online services may help alleviate the challenges. Broader access to qualified medical professionals, such as provided by HealthTAP [45], may alleviate the tendency of users to seek medical advice from forums $[45,46]$.

The online community is dynamic and growing. Increasingly individuals are turning to the Internet for volunteering and opportunities to participate collectively in projects with positive social impacts. The most novel aspect of PFOND is the focus on the volunteer for the creation and dynamic development of websites focused on communities impacted by rare disorders. An enduring volunteer-powered resource allows for an online community to form and to continually benefit from new information and insights into the challenges faced at different life stages by those impacted by a disorder.

\section{Future Directions}

Three areas of activity are expected in the next iteration of PFOND development. First, the existing system can be extended to better support users with accessibility challenges, such as limited vision. Second, the system can be made available to a broader range of volunteer editors who can contribute to building and improving the site. Third, the framework of PFOND will allow for structured, quantitative research of both user and volunteer editor engagement/satisfaction and editor performance when provided with distinct gamification features or innovative design elements. In the longer term, there may be opportunities to promote exchange between related PFOND communities. Each of the future directions brings challenges.

Users of PFOND are more likely to be challenged by impairments than the average Internet user. Thus, the further development of PFOND will require greater attention to the issue of website accessibility, which can be addressed by increasing the flexibility of the design. The pilot version has been designed to be easily navigated, but additional work will be required to make it accessible, particularly for users with low vision [47]. While the use of WordPress as the underlying system will allow assistive software to be applied [48], there are additional steps that can be taken in the next iteration of PFOND. Users can be empowered to change display settings to use larger font sizes, increase line spacing, and apply more contrasting colors. Site editors will need structured training to configure these options to suit their target audience (for example, the aniridia site could use more readable fonts by default). The introduction of the assistive features is a key step moving forward.

The ultimate goal for PFOND is the engaged participation of volunteer editors from around the globe. The current prototype was tested within the geographic confines of one university, with extensive oversight of the initial cadre of participants. In the second phase, the system can be modified to minimize supervisory time, allowing senior volunteer editors to take on additional supervisory activities, while empowering the development team to maintain an overview of the material being posted each day. In the second phase, we will disseminate calls for participation across volunteer recruitment boards, both in global posting boards (eg, VolunteerMatch) and in directed fashion to volunteer boards serving specific communities such as university students [49].

Appropriate gamification mechanisms are especially important for the system to succeed on a large scale. Inappropriately implemented gamification could decrease editor engagement, creating a perception of decreased social value if such extrinsic motivation mechanisms are required [35]. An irrelevant and enforced scoring system relying on points, leaderboards, and badges can do more harm than good. The current PFOND system has emphasized intrinsic motivation (as seen in Table 3 ), in addition to points and leaderboards. When users are able to connect their goals to values they hold, a better outcome might be expected. However, there is limited published research on the effectiveness of game-like elements to promote patterns 
of activity within Internet-based community service systems. We will implement additional gamification features, including badges, and measure how effective they are in motivating editors to finish a website, using the PFOND framework to compare and contrast distinct approaches on the successful completion of PFOND sites and on user satisfaction and perception.

For such measurements, one potential user survey is WAMMI (Website Analysis and Measurement Inventory), a 60-item questionnaire, but an average user may be unlikely to complete such a long instrument [50]. A shorter survey developed by van Schaik and Ling (2009) assesses user perceptions of ease of use, utility disorientation, flow, and aesthetics [51]. The reliability and validity of the scales have been confirmed. The experience of editors can be measured with a different survey, as they use a different interface with less Web-like design. The Software Usability Measurement Inventory (SUMI) is intended for such non-Web user interfaces [52] but conveniently shares similarities with WAMMI [51].
The PFOND site incorporates some innovative design features, but in the next phase it will be possible to measure the impact of a series of features. The first phase emphasis on content building limited, but did not preclude, innovation. For instance, the PFOND site includes dynamically updating elements and static summaries in partnership to better address the transient nature of editor participation. In the next wave of the project, flexibility for innovation will be added to the system. In addition to the accessibility features addressed above, we will encourage volunteer editors to review the IDEO Methods Cards App in order to inspire potential features [53]. Through this community participation, we will identify a subset of innovative features to test within the system, providing a subset of editors with the design feature and measuring their perception using validated surveys.

The solid computational foundation introduced in this report lays the groundwork for a broader international volunteer effort for creating online resources for families struggling with rare disorders.

\section{Acknowledgments}

Funding for this research was provided by the Sharon Stewart Trust for Aniridia Research, the Treatable Intellectual Disorders Endeavour (funded by the BC Children's Hospital Foundation), the Canadian Institutes for Health Research, and the Canada Foundation for Innovation (to the Gene Regulation Bioinformatics Laboratory). We express our gratitude for IT support from Jonathan Lim, Jonathan Chang, and Miroslav Hatas, and research management from Dora Pak. The NeuroDevNet Network Centre of Excellence provided the initial inspiration for the project by promoting exchanges between research scientists and communities challenged by neurodevelopmental disorders.

\section{Conflicts of Interest}

None declared.

\section{Multimedia Appendix 1}

Steps to establish a new PFOND site. (a) In the first step, volunteers submit an application to serve as an editor. (b) Accepted editors use an intuitive admin interface to create a PFOND site. (c) Editors collect and update their site with disease information, relevant news items, pertinent links, and field experts. (d) When ready, editors publish a PFOND site making it accessible to all readers. (e) The new site is added to the PFOND homepage and is indexed by search engines for increased exposure.

\section{[PNG File, 2MB-Multimedia Appendix 1]}

\section{References}

1. Eysenbach G, Köhler C. Health-related searches on the Internet. JAMA 2004 Jun 23;291(24):2946. [doi: 10.1001/jama.291.24.2946] [Medline: 15213205]

2. Fox S. Pew Internet. Washington, DC: Pew Internet \& American Life Project; 2011. The Social Life of Health Information, 2011 URL: http://www.pewinternet.org/ /media//Files/Reports/2011/PIP Social Life of Health Info.pdf [accessed 2013-07-16] [WebCite Cache ID 6IA8sRqAO]

3. Fox S, Duggan M. Pew Internet. Washington, DC: Pew Internet \& American Life Project; 2013. Health Online 2013 URL: http://www.pewinternet.org/ /media//Files/Reports/PIP HealthOnline.pdf [accessed 2013-07-12] [WebCite Cache ID 6I40RO3WV]

4. Wood FB, Benson D, LaCroix EM, Siegel ER, Fariss S. Use of Internet audience measurement data to gauge market share for online health information services. J Med Internet Res 2005 Jul 1;7(3):e31 [FREE Full text] [doi: 10.2196/jmir.7.3.e31] [Medline: 15998622]

5. Gonzaga-Jauregui C, Lupski JR, Gibbs RA. Human genome sequencing in health and disease. Annu Rev Med 2012;63:35-61. [doi: 10.1146/annurev-med-051010-162644] [Medline: 22248320]

6. Kaphingst KA, McBride CM, Wade C, Alford SH, Brody LC, Baxevanis AD. Consumers' use of web-based information and their decisions about multiplex genetic susceptibility testing. J Med Internet Res 2010;12(3):e41 [FREE Full text] [doi: 10.2196/jmir.1587] [Medline: 20884465] 
7. Iredale R, Mundy L, Hilgart J. An online resource of digital stories about cancer genetics: qualitative study of patient preferences and information needs. J Med Internet Res 2011;13(3):e78 [FREE Full text] [doi: 10.2196/jmir.1735] [Medline: $\underline{22057223]}$

8. DeLuca JM, Kearney MH, Norton SA, Arnold GL. Internet use by parents of infants with positive newborn screens. J Inherit Metab Dis 2012 Sep;35(5):879-884. [doi: 10.1007/s10545-011-9449-7] [Medline: 22297410]

9. Amberger J, Bocchini C, Hamosh A. A new face and new challenges for Online Mendelian Inheritance in Man (OMIM®). Hum Mutat 2011 May;32(5):564-567. [doi: 10.1002/humu.21466] [Medline: 21472891]

10. Laurent MR, Vickers TJ. Seeking health information online: does Wikipedia matter? J Am Med Inform Assoc 2009 Aug;16(4):471-479 [FREE Full text] [doi: 10.1197/jamia.M3059] [Medline: 19390105]

11. Heilman JM, Kemmann E, Bonert M, Chatterjee A, Ragar B, Beards GM, et al. Wikipedia: a key tool for global public health promotion. J Med Internet Res 2011;13(1):e14 [FREE Full text] [doi: 10.2196/jmir.1589] [Medline: 21282098]

12. De la Torre-Díez I, Díaz-Pernas FJ, Antón-Rodríguez M. A content analysis of chronic diseases social groups on Facebook and Twitter. Telemed J E Health 2012 Aug;18(6):404-408. [doi: 10.1089/tmj.2011.0227] [Medline: 22650380]

13. Wicks P, Massagli M, Frost J, Brownstein C, Okun S, Vaughan T, et al. Sharing health data for better outcomes on PatientsLikeMe. J Med Internet Res 2010;12(2):e19 [FREE Full text] [doi: 10.2196/jmir.1549] [Medline: 20542858]

14. EyesApart: Eyes Apart Strabismus Support. URL: http://health.groups.yahoo.com/group/EyesApart/ [accessed 2013-07-12] [WebCite Cache ID 6I40NCAII]

15. Huntington's Disease Society of America. URL: http://www.hdsa.org/ [accessed 2013-04-18] [WebCite Cache ID 6Fyg5tIYG]

16. Cystic Fibrosis Foundation. URL: http://www.cff.org/ [accessed 2013-04-18] [WebCite Cache ID 6FygH7zS8]

17. Eurordis. Rare Diseases: Understanding this Public Health Priority URL: http://www.eurordis.org/IMG/pdf/ princeps document-EN.pdf [accessed 2013-07-12] [WebCite Cache ID 6I42fzf8X]

18. Groft SC, de la Paz MP. Rare diseases - avoiding misperceptions and establishing realities: the need for reliable epidemiological data. Adv Exp Med Biol 2010;686:3-14. [doi: 10.1007/978-90-481-9485-8 1] [Medline: 20824436]

19. Berland GK, Elliott MN, Morales LS, Algazy JI, Kravitz RL, Broder MS, et al. Health information on the Internet: accessibility, quality, and readability in English and Spanish. JAMA 2001;285(20):2612-2621. [Medline: 11368735]

20. Risoldi Cochrane Z, Gregory P, Wilson A. Readability of consumer health information on the internet: a comparison of U.S. government-funded and commercially funded websites. J Health Commun 2012;17(9):1003-1010. [doi: 10.1080/10810730.2011.650823] [Medline: 22512714]

21. Brewer GJ. Drug development for orphan diseases in the context of personalized medicine. Transl Res 2009 Dec;154(6):314-322. [doi: 10.1016/j.trsl.2009.03.008] [Medline: 19931198]

22. Lasker JN, Sogolow ED, Sharim RR. The role of an online community for people with a rare disease: content analysis of messages posted on a primary biliary cirrhosis mailinglist. J Med Internet Res 2005;7(1):e10 [FREE Full text] [doi: 10.2196/jmir.7.1.e10] [Medline: 15829472]

23. Knight AW, Senior TP. The common problem of rare disease in general practice. Med J Aust 2006 Jul 17;185(2):82-83. [Medline: 16842062]

24. Skinner D, Schaffer R. Families and Genetic Diagnoses in the Genomic and Internet Age. Infant Young Child 2006;19(1):16-24.

25. Henning J. The Blogging Iceberg: Of 4.12 Million Hosted Weblogs, Most Little Seen, Quickly Abandoned. URL: http:/ /www.perseusuk.co.uk/survey/news/releases/release blogs.html [accessed 2013-03-29]

26. Patsos M. MSJAMA: the Internet and medicine: building a community for patients with rare diseases. JAMA 2001 Feb 14;285(6):805. [Medline: 11176922]

27. van Uden-Kraan CF, Drossaert CH, Taal E, Seydel ER, van de Laar MA. Patient-initiated online support groups: motives for initiation, extent of success and success factors. J Telemed Telecare 2010;16(1):30-34. [doi: 10.1258/jtt.2009.001009] [Medline: 20086265]

28. Patel SK, Rathod VR, Prajapati JB. Performance Analysis of Content Management Systems - Joomla, Drupal and WordPress. International Journal of Computer Applications 2011 May 31;21(4):39-43. [doi: 10.5120/2496-3373]

29. WordPress.com - Get a Free Blog Here. URL: http://wordpress.com/ [accessed 2013-04-18] [WebCite Cache ID 6FygMTt10]

30. WordPress Plugins. URL: http://wordpress.org/extend/plugins/ [accessed 2013-04-18] [WebCite Cache ID 6FygXDVNR]

31. GitHub Software Repository - PFOND Software. URL: https://github.com/pfond/PFOND [accessed 2013-07-22] [WebCite Cache ID 6IJU8xQfr]

32. Yusuf D, Butland SL, Swanson MI, Bolotin E, Ticoll A, Cheung WA, et al. The transcription factor encyclopedia. Genome Biol 2012;13(3):R24 [FREE Full text] [doi: 10.1186/gb-2012-13-3-r24] [Medline: 22458515]

33. Deterding S, Dixon D, Khaled R, Nacke L. From game design elements to gamefulness: defining “gamification”. In: Proceedings of the 15th International Academic MindTrek Conference: Envisioning Future Media Environments. 2011 Presented at: International Academic MindTrek Conference: Envisioning Future Media Environments; Sept. 28-30, 2011; New York, NY, USA.

34. Groh F. Gamification: State of the Art Definition and Utilization. In: Proceedings of the 4 th Seminar on Research Trends in Media Informatics. Germany: Institute of Media Informatics, Ulm University; 2012 Presented at: The 4th Seminar on Research Trends in Media Informatics; 14th Febuary, 2012; Ulm, Germany p. 39-46. 
35. Nicholson S. A User-Centered Theoretical Framework for Meaningful Gamification. In: Proceedings of GLS 80 Games + Learning + Society Conference. 2012 Presented at: GLS 80 Games + Learning + Society Conference; June 13-15, 2012; Madison, Wisconsin.

36. Deci EL, Ryan RM. Intrinsic motivation and self-determination in human behavior. New York: Plenum; 1985.

37. Hewitt-Taylor J, Bond CS. What e-patients want from the doctor-patient relationship: content analysis of posts on discussion boards. J Med Internet Res 2012;14(6):e155 [FREE Full text] [doi: 10.2196/jmir.2068] [Medline: 23137788]

38. Gundersen T. 'One wants to know what a chromosome is': the internet as a coping resource when adjusting to life parenting a child with a rare genetic disorder. Sociol Health Illn 2011 Jan;33(1):81-95. [doi: 10.1111/j.1467-9566.2010.01277.x] [Medline: 20937053]

39. Schaffer R, Kuczynski K, Skinner D. Producing genetic knowledge and citizenship through the Internet: mothers, pediatric genetics, and cybermedicine. Sociol Health Illn 2008 Jan;30(1):145-159. [doi: 10.1111/j.1467-9566.2007.01042.x] [Medline: $\underline{18254838}$

40. Tozzi AE, Mingarelli R, Agricola E, Gonfiantini M, Pandolfi E, Carloni E, et al. The internet user profile of Italian families of patients with rare diseases: a web survey. Orphanet J Rare Dis 2013 May 16;8(1):76 [FREE Full text] [doi: 10.1186/1750-1172-8-76] [Medline: 23680013]

41. Frost JH, Massagli MP. Social uses of personal health information within PatientsLikeMe, an online patient community: what can happen when patients have access to one another's data. J Med Internet Res 2008;10(3):e15 [FREE Full text] [doi: 10.2196/jmir.1053] [Medline: 18504244 ]

42. Ziebland S, Wyke S. Health and illness in a connected world: how might sharing experiences on the internet affect people's health? Milbank Q 2012 Jun;90(2):219-249. [doi: 10.1111/j.1468-0009.2012.00662.x] [Medline: 22709387]

43. Greene JA, Choudhry NK, Kilabuk E, Shrank WH. Online social networking by patients with diabetes: a qualitative evaluation of communication with Facebook. J Gen Intern Med 2011 Mar;26(3):287-292 [FREE Full text] [doi: 10.1007/s11606-010-1526-3] [Medline: 20945113]

44. Routh JC, Gong EM, Nelson CP. Pediatric urology and the internet--does an uncommon topic decrease content quality? J Urol 2009 Oct;182(4):1569-1574. [doi: 10.1016/j.juro.2009.06.056] [Medline: 19683756]

45. HealthTap. URL: https://www.healthtap.com/ [accessed 2013-04-18] [WebCite Cache ID 6FyggZJeB]

46. Dizon DS, Graham D, Thompson MA, Johnson LJ, Johnston C, Fisch MJ, et al. Practical guidance: the use of social media in oncology practice. J Oncol Pract 2012 Sep;8(5):e114-e124 [FREE Full text] [doi: 10.1200/JOP.2012.000610] [Medline: 23277774]

47. Wentz B, Cirba N, Kharal N, Moran J, Slate M. Evaluating the Accessibility and Usability of Blogging Platforms for Blind. London: Langdon P, Clarkson J, Robinson P, Lazar J, Heylighen A. editors. Designing Inclusive Systems. Springer London; 2012:43-52.

48. WordPress Codex. Accessibility URL: http://codex.wordpress.org/Accessibility [accessed 2013-04-18] [WebCite Cache ID 6FykAKNeK]

49. VolunteerMatch - Where Volunteering Begins. URL: http://www.volunteermatch.org/ [accessed 2013-07-11] [WebCite Cache ID 6I2ge4IgA]

50. Kirakowski J, Cierlik B. Measuring the Usability of Web Sites. In: Proceedings of the Human Factors and Ergonomics Society Annual Meeting. 1998 Presented at: Human Factors and Ergonomics Society Annual Meeting; Oct. 1, 1998; Chicago p. 424-428.

51. van Schaik P, Ling J. Five Psychometric Scales for Online Measurement of the Quality of Human-Computer Interaction in Web Sites. International Journal of Human-Computer Interaction 2005 Jul;18(3):309-322. [doi:

10.1207/s15327590ijhc1803 4]

52. What is SUMI?. URL: http://sumi.ucc.ie/whatis.html [accessed 2013-07-11] [WebCite Cache ID 6I2kSfQ71]

53. Method Cards | IDEO. URL: $\underline{\text { http://www.ideo.com/work/method-cards/ [accessed 2013-07-11] [WebCite Cache ID }}$ $\underline{6 \mathrm{I} 2 \mathrm{kwbNq} 5]}$

\section{Abbreviations}

AFI: Aniridia Foundation International

ASS: Aarskog-Scott Syndrome

CF: cystic fibrosis

CMS: Content Management System

OMIM: Online Mendelian Inheritance in Man

PFOND: Portal for Families Overcoming Neurodevelopmental Disorders

SUMI: Software Usability Measurement Inventory

WAMMI: Web Site Analysis and Measurement Inventory 
Edited by G Eysenbach; submitted 29.04.13; peer-reviewed by P Nambisan, $R$ Lin; comments to author 15.06.13; revised version received 11.07.13; accepted 12.07.13; published 06.08.13

Please cite as:

Ye XC, Ng I, Seid-Karbasi P, Imam T, Lee CE, Chen SY, Herman A, Sharma B, Johal G, Gu B, Wasserman WW

Portal for Families Overcoming Neurodevelopmental Disorders (PFOND): Implementation of a Software Framework for Facilitated Community Website Creation by Nontechnical Volunteers

JMIR Res Protoc 2013;2(2):e25

URL: http://www.researchprotocols.org/2013/2/e25/

doi: 10.2196/resprot.2675

PMID: 23920006

(CXin Cynthia Ye, Isaiah Ng, Puya Seid-Karbasi, Tuhina Imam, Cheryl E. Lee, Shirley Yu Chen, Adam Herman, Balraj Sharma, Gurinder Johal, Bobby Gu, Wyeth W. Wasserman. Originally published in JMIR Research Protocols (http://www.researchprotocols.org), 06.08.2013. This is an open-access article distributed under the terms of the Creative Commons Attribution License (http://creativecommons.org/licenses/by/2.0/), which permits unrestricted use, distribution, and reproduction in any medium, provided the original work, first published in JMIR Research Protocols, is properly cited. The complete bibliographic information, a link to the original publication on http://www.researchprotocols.org, as well as this copyright and license information must be included. 